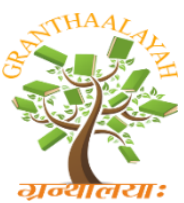

$$
\begin{gathered}
\text { INTERNATIONAL JOURNAL OF RESEARCH - } \\
\text { GRANTHAALAYAH } \\
\text { A knowledge Repository }
\end{gathered}
$$

Science

\title{
A REVIEW PAPER ON CONTROLLING OF THREE PHASE \& SINGLE PHASE ELECTRICAL EQUIPMENT BY USING IOT, GSM \& WI-FI
}

\author{
Devanand K. Patil ${ }^{* 1}$, Kaveri G. Avhad ${ }^{2}$, Prathamesh C. Johore ${ }^{3}$, Madhuraj K. Sharma ${ }^{4}$ \\ ${ }^{* 1,2,3}$ UG Student, Department of Electrical Engineering, SIEM, Nashik, SPPU, Pune \\ Maharashtra, India \\ ${ }^{4}$ Assistant Professor, Department of Electrical Engineering, SIEM, Nashik, SPPU, Pune \\ Maharashtra, India
}

DOI: https://doi.org/10.29121/granthaalayah.v5.i3.2017.1760

\begin{abstract}
In this review work the study was done to control the external operation of electrical appliances, the electrical or electronic appliances connected to this system from far away from the operator. For this purpose user can use android type of mobile. Using the IOT, GSM \& Wi-Fi we can switch and fault detection of the electrical devices/appliances. This work will be beneficial for agricultural, industrial, domestic, commercial projects also. Automation done in this field is shown here by using the literature review, various authors has worked in the same field and by using different ways. Some authors used vlsi embedded system some used algorithms some used programs some used automation and some used the electronic applications. This work is totally different from others. We used here the circuit diagram and the GSM module and WiFi modules are connected in this circuit to the unit 5 that is ATMEGA328P.That signal is proceed to the controller for further operation. At the load side the load should be either 1-phase or 3-phase. As per the application it depends on the user.
\end{abstract}

Keywords: Android; Electrical Devices; GSM; IOT; Wi-Fi.

Cite This Article: Devanand K. Patil, Kaveri G. Avhad, Prathamesh C. Johore, and Madhuraj K. Sharma. (2017). "A REVIEW PAPER ON CONTROLLING OF THREE PHASE \& SINGLE PHASE ELECTRICAL EQUIPMENT BY USING IOT, GSM \& WI-FI.” International Journal of Research - Granthaalayah, 5(3), 135-139. 10.29121/granthaalayah.v5.i3.2017.1760.

\section{Introduction}

The work done by us is the development of circuit by using IoT, GSM and WiFi and the equipments can be handled from different places. This work will be beneficial for agricultural, industrial, domestic, commercial projects also. Automation done in this field is shown here by using the literature review, various authors has worked in the same field and by using different ways. Some authors used vlsi embedded system some used algorithms some used programs some 
used automation and some used the electronic applications. This work is totally different from others. We used here the circuit diagram and the GSM module and WiFi modules are connected in this circuit to the unit 5 that is ATMEGA328P. The ports of the unit are connected with two modules. Again these unit 5 is connected with different four units and then to the load. The system is pure circuit base and not program base. We have done the literature review for this work. And published the review work over here. All authors are made their conclusions and the results made here. Maheshkumar M. Jangid, et al. (2016) published the work on Android application for single phase motor control using IVRS and GSM in this study they focused on android is software used for mobile devices that includes a system of operating, middle ware and main applications. They used android apps are made in a languages like java and running on an implicit machine known as Dalvik created by Microsoft. They also applied the android sdk provides the tools and apps necessary to start developing applications on the android platform using the java programming language. The purpose of the final application is to help farmer to use easily with the regional language. They used the design of the self-made design. The project will be designed to develop an application in android motor control system. The 4 operation of the alternating current motor is better suited for companies where device like motor is used and as per need as they work on android cellphones. Also the author putted the point that in case of a specific operation in industrial environment, the motor needs to be stopped immediately. In such situation author said, this estimated system is very easy as we can aptly perform operations on time to set powered device, to set time by auto time switch, under voltage settlement, over voltage, motor off time and many more like are its integral importance. Also author said that the motor which is running for a more period and the operational things control of the runningmotor can be achieved with the micro-controller. ${ }^{[1]}$ Lokesh Heda et al. (2016) worked on Fault monitoring and protection of three phase devices this paper focuses on monitoring and protection of three phase equipment's using PIC micro-controller and radio frequency receiver as well as transmitter. Medium scale industries always periodically came across the over voltage problem, under voltage, over current, under current, overheating, and earthing fault in three phases. Therefore to avoid or to minimize the problem mentioned above, anybody can protect their three phase appliances or equipment by using different methods. With all other classical approaches the use of contactors is also used putted by the authors, voltage relays as well as current relays. Due to advance features of computers and microcontrollers now a day this method is not so used. The system which they had stated in their work is a micro-controller based hardware system and used for tracking of things such as over and under voltage, over temperature, earth fault and 1 phase. The system was also interfaced using RF module by the authors to computer software which was unitedly displayed parameter values. The system made by those authors was capable to start the device by automatically itself as the recovering of parameters. They also said that a power supply has always been a top priority base for the scholars, researchers as well as engineers and working for the industrial development. They had pointed up with few methods of fault analysis and stabilizing like monitoring of vibration, temperature and heat monitoring, monitoring of chemicals these entire specialized tool requires for methods of monitoring and sensors which were very costly, whereas parametric monitoring using micro-controller and CC2500 reduces the use of additional sensors. The results drawn from the experiment shows that hardware system based on micro-controller gives very high perfection and accuracy as well as safety and best environmental compare to the conventional mechanical based systems. In their study paper, they introduced a method for safety of three phase equipment's using a PIC micro-controller. With the help of microcontroller, they were 
continuously monitored the parameter for protecting the load from bad and harmful parameter values. They were also provided self-investigation which told them the problem has occurred by which parameter and if the parameter recovers its specified value then system will auto reset itself. ${ }^{[2]}$ Biswarup Nandi et al. (2015) worked on the GSM based pump automation In that work the project GSM based pump automation had modified to run a motor using GSM appliance, such as cellphone. That work is particularly designed to run motors and submersible pumps located at remote places and for agricultural benefit purpose, farmers and small scale companies where remote pump and motor control necessary. Their project was designed with quality process and advanced micro-controller technique. A checking procedure was also used that valid user had topmost power to operate its use by other users. If the person used top power and allows other users to ON/OFF the pump or motor then only it can be handled by specifically that single user only. One list of authenticated users will be controlled such that if main person authenticate an user to operate the pump module will not inform the owner anymore to authenticate the registered user. Their checking up was required to prevent the wrong use of that module. Population of India has increased three times, but production of food and grain more than four times there had thus been tremendous increase in food and grain available per capita. Mainly, a tremendous amount of time and energy was wasted by a user or a farmer to go his farm for on and of pump and motor. The person has to move to farms often during critical hours and in difficult weather just to operate the motor due to bad and irregular power supply based on algorithms and programs. ${ }^{[3]}$ Pooja S.Billade and Sanjay S. Chopade, (2015) worked on 3 phase induction motor control using single phase input and GSM. The authors used controller in this work is a remote speed control using a GSM technique that proves to be very much effective and reliable in applications. The general principle was the constant voltage and frequency principle which needs that the voltage magnitude and voltage frequency applied to the stator of a motor maintain a constant ratio. By doing this, the value of the magnetic field in the stator is kept at an tentatively constant level throughout the working range. Thus, maximum constant torque making capability is maintained. Author also stated that the energy that a starter power translator delivers to a motor was controlled by signals with modulated pulse applied to the gates of the power transistors in $\mathrm{H}$ bridge configuration. PWM signals are pulse trains with fixed frequency and magnitude and variable pulse width. When a PWM signal was used to the gate of a power transistor, it affects the on and off and turns off intervals of the transistor to change from one PWM period. In a very wide power range motor drives were used. In applications like speed adjustable drive the ranges of speed achievable is very important in applications such as c controlling of a boiler feed-water pump. In all drives where the speed and position are controlled, a power electronic converter is required as an relation between the input power and the motor. Author also stated that a controller was also required to make the motor, through the power electronic converter, meet the drive requirements. Effectively, the effective automation in large scale industries demand several styles that have high reliability and effective to be introduced and one of the main needs were the control technique used. The controller used in this work is a remote to control speed using a GSM technology that proves to be very efficient and reliable in applications $^{[4]}$. G. R. Sreehitha et al., (2012) Control of a three phase induction motor using single phase supply, In commercial applications, 2 types of electrical currents are used, direct current \& alternating currents. Usually constant voltage and frequency 1 Phase or 3 Phase AC is readily available. However, for various applications various frequencies, magnitudes and or forms are useful. Their work in their paper gives how the 3 phase inductive load is run by a 1 phase supply by using cyclometer and a scott-T connected transformer. They also putted that the 
controlling of a 3 phase induction motor was done by frequency variable method. 1 phase to 3 phase for motors offered by using high in performance, low on maintenance and is used to reduce of breakdown of electrical equipment, our range is also suitable for saving energy and require low maintenance. Their paper draws a new technology for controlling a 3 phase induction motor with single phase current supply. They also used cycloconverter to control the firing pulses. With the help of changed frequencies, variable speeds achieved of a three phase induction motor ${ }^{[5]}$. S.Sumeetha, D.Sharmila (2012) worked on embedded based remote control application using mobile phone in irrigation, This work and paper provides the use of cellphones as a remote to control induction motor as well as pump application for the which is used in the agriculture for irrigation. Due to irregular and discontinuous power supply and fluctuating voltage conditions in our nation India, it is very top priority to give water supply effectively to the farm during normal conditions. Also they added the point that this is continued by changing the signals between the cellphone of user and module in the form of text message or call. This system is made with PIC16F877A microcontroller which is connected to the cellphone and sensors and the motor. The thermal sensor is utilized to detect the thermal changes of the environment and capacitive sensor to sense the flow of water in the closed conduit. The microcontroller covers the safety against over current, dry running and 1 phase. They putted the information that it is needful that their application provides simple access of motor to a great extent. Water supply is the planning science and efficient designing, cheap, economic water supply system tailored to fit natural conditions by the construction of proper distribution system, the yield of crop may be increased because of controlled water supply. The various methods of water supply to the farm are, subsurface irrigation and sprinkler water supply. The water is distributed to the agricultural farm through few good and simple water supply system ${ }^{[6]}$. V. Bhaskar, T. Gowri Manohar., (2011) published there work in GSM based motor monitoring and speed control, In that paper they emphasizes the design aspects of an device which was embedded which can make control over up to eight equipments by sending a particular text message from a cellphone were presented by them. The author added that controller was effective and small and less space consuming also it is able to move in pocket also at places where we have to control the switching of the equipment also wireless connection also do the work. Also to use and implement this, a modem is connected to a microcontroller which was programmed which would receive the text message from a reference mobile phone. The control signal part of the received SMS is extracted and is changed to microcontroller-preferred format. They pointed out the a PC which is connected to the microcontroller using a serial communication through RS232 can be used for monitoring and transmission of the control signals to the modem. They also pointed that the monitoring is also done by interfacing a LCD to the microcontroller. In the project work undertaken, GSM technology based automatic control system is designed to monitor and control speed of an Induction motor/DC motor and also performs necessary operation like start, stop, reverse the rotation text. ${ }^{[7]}$

\section{Results and Discussions}

The review work done over here is very useful for the next design work of the GSM model. The main focus on literature review is due to the review is very key player in the field of research. The review was done rigorously. The various papers were discussed here with their authors some authors are very greatly done their work. The research gaps can be found out from this review work. The effect of the development of this circuit is very positive. The use of the GSM, WiFi 
units are assures that the controlling is very efficiently and advance. The use of the five units to control the main part of the signal. This project work surely helps in the field of agriculture where farmer is very badly suffering from negative conditions and adversely situations. The signals send to that part are very useful.

\section{Conclusions}

The review will surely helped for the next research in the same field. Based on this study work the controlling of the electrical equipment can be done by using the IoT, GSM and Wi-Fi. The previous study done by authors hasn't used this devices, also hasn't made simultaneous study. The main focus in this study is to switch and fault detection of electrical equipment and controlling it by command from another place. The study done here is the literature review for next work. The work will be done by using circuit diagram and the android application.

\section{Acknowledgements}

We would like to convey our special gratitude and appreciation towards Prof M. K. Sharma, Prof. Piyush M. Desai Prof. Patel and HOD Dr. D. P. Kadam for their continuous motivation and valuable assistance in this review work.

\section{References}

[1] Maheshkumar M. Jangid, Rahul P. Matere, Jayesh D. Patil, Rohit K. Vadnere, Jitendra S. More \& Prof. U. R. Patole, Android Application for Single Phase Motor Control Using IVRS and GSM, International Journal of Interdisciplinary Research. Vol. 2, Iss 12, 2016, 1632-1635.

[2] Lokesh Heda, Pritesh Bhutada, Rinkesh Thakur, Piyush Bhattad, Vinita Singh, Fault Monitoring and Protection of Three Phase Devices, International Journal of Innovative Research in Electrical, Electronics, Instrumentation and Control Engineering, Vol. 4, Iss. 4, 2016, 208-210.

[3] Biswarup Nandi, Soumi Mondal, Kuntal Ghosh, Rana Biswas, GSM Based Pump Automation, International Journal of Advanced Research in Computer Science and Software Engineering, 2015, Vol. 5, Iss. 9, 446-452.

[4] Pooja S.Billade, Sanjay S. Chopade, 3 Phase Induction Motor Control Using Single Phase Input and GSM. International Journal of Advanced Research in Electrical, Electronics and Instrumentation Engineering, Vol. 4, Iss. 6 .2015, 5006-5011.

[5] G. R. Sreehitha, A. Krishna Teja, Kondenti. P. Prasad Rao., Control of a Three Phase Induction Motor using Single Phase Supply, International Journal of Engineering Trends and Technology, Vol. 3, Iss. 3, 2012, 413-436.

[6] S.Sumeetha, D.Sharmila. Embedded based Remote Control Application using Mobile Phone in Irrigation, International Journal of Power Control Signal and Computation, Vol. 3, Iss. 1, 2012, 76-79.

[7] V. Bhaskar, T. Gowri Manohar., GSM Based Motor Monitoring and Speed Control, International Journal of Mechanical and Industrial Engineering, Vol. 1, Iss. 2, 2011, 87-92.

*Corresponding author.

E-mail address: devanandkpatil@gmail.com 